\title{
La historia clínica en el proceso judicial por responsabilidad médica en Cuba. Alcance y valor probatorio
}

\author{
Recibido: 25 de mayo de 2020 • Aprobado: 19 de julio de 2020 \\ https://doi.org/10.22395/ojum.v20n42a17
}

\author{
Liuver Camilo Momblanc \\ Universidad de Oriente, Santiago de Cuba, Cuba \\ liuverc@uo.edu.cu \\ https://orcid.org/0000-0002-1311-095X
}

\section{RESUMEN}

El presente texto persigue como propósito principal analizar el alcance y valor probatorio de la historia clínica en el ámbito jurídico-procesal a la luz del ordenamiento jurídico cubano frente a la discutida definición de su carácter de documento público o privado. Como objetivo secundario, se pretende enunciar aquellos factores que constituyen riesgos legales asociados a la historia clínica e inciden en su valor probatorio. Con tales designios, la metodología seguida estuvo sustentada esencialmente en los métodos analítico-sintético, inductivo-deductivo y el hermenéutico, aplicados en el marco de una indagación de tipo documental, argumentativa y exploratoria. Entre los resultados se muestra el comportamiento del estado del arte del tema en el país y las falencias legales en este aspecto. La conclusión señala la necesidad de armonizar la legislación de salud, que se refiere a la historia clínica, con las exigencias establecidas desde nuestra norma procesal civil en cuanto al carácter público o privado de los documentos.

Palabras clave: riesgo legal; prueba documental; documento público; documento privado; mala praxis. 


\title{
The Medical History in the Judicial Process for Medical Responsibility in Cuba: Scope and Probative Value
}

\begin{abstract}
The main purpose of this text is to analyze the scope and evidentiary value of clinical history in the legal-procedural field, in the light of the Cuban legal system as opposed to the disputed definition of its character as a public or private document. As a secondary objective, it seeks to identify those factors that constitute legal risks associated with clinical history and that affect their evidentiary value. With these aims, the methodology followed was essentially based on the methods of analysis-synthesis, induction-deduction and hermeneutics, applied within the framework of a documentary, argumentative and exploratory type of investigation. Among the results, the behavior of the state of the art of the subject in the country and the legal shortcomings in this aspect are shown. The conclusion points out the need to harmonize the health legislation that refers to the clinical history with the requirements established from our civil procedural norm regarding the public or private character of the documents.
\end{abstract}

Keywords: legal risk; documentary evidence; public document; private document; malpractice. 


\section{INTRODUCCIÓN}

Este artículo se desarrolla en el marco de las actividades investigativas del autor. Este es doctorando del programa de Doctorado en Ciencias Jurídicas de la Universidad de Oriente de Santiago de Cuba, acreditado con la condición de excelencia por la Junta de Acreditación Nacional de Cuba y mención de honor de la Asociación Universitaria Iberoamericana de Posgrado (AUIP) con sede en España. El autor también se inserta dentro del proyecto institucional Convencionalidad y política criminal del Departamento de Derecho Penal, Empresarial e Internacional de la Facultad de Derecho de la propia institución de educación superior.

En la intitulada "sociedad de la Información" se significa que la información como recurso es uno de los factores más importantes para el éxito de cualquier proceso. Disponer con rapidez de una información completa y fiable constituye un elemento esencial para mejorar la calidad de los servicios que ofrecen las diferentes instituciones, entre otras razones, porque constituye un intangible esencial para la correcta toma de decisiones (Ponjuán, 2008). De igual modo, porque sin importar su soporte, físico o digital, sirve como evidencia del cumplimiento de las obligaciones legales.

En el ámbito médico, la información que se genera, utiliza y almacena durante la actuación terapéutica se encuentra orientada bajo el eje cardinal de la finalidad asistencial. Esta información se registra en un documento creado para tales fines que universalmente se conoce como historia clínica (HC). No obstante, como ocurre en otros sectores de actividad, también puede tener una serie de usos diferenciados de aquel que la origina stricto sensu. Entre ellos, se encuentran -con independencia de los riesgos que en algunos casos pueda suponer a la protección del derecho a la intimidad del paciente (Monje Balmaseda, 2012)- los usos administrativos, judiciales, de investigación, de docencia, entre otros (Gutiérrez Barrenengoa, 2012; Herrán Ortiz, 2012; Silvia Velito y Tejada Soriano, 2010).

La HC se define como el conjunto de documentos que contienen de forma ordenada y detallada aquellos datos y valoraciones sobre la evolución y la situación clínica de un paciente. Estos datos son refrendados por los médicos tratantes u otro personal de la salud, durante las asistencias que el paciente reciba desde el ingreso hasta el egreso del centro médico (Castellano Arroyo y Gisbert Calabuig, 2005; Siso Martín, 2017; Valenti, 2017). No es por ello de extrañar, que amén de su orientación asistencial, tenga otras utilidades con repercusiones jurídicas, entre las cuales se significa su papel en el terreno jurídico-procesal por su valor probatorio (Gutiérrez Barrenengoa, 2012; Lombana Villalba, 2010; Vila Morales y Pérez Echeverría, 2012). De ahí su carácter protagónico y, en ocasiones, definitivo en los procesos de responsabilidad médica junto a la prueba pericial, a la cual también sirve de fundamento (Siso Martín, 2017; Lombana Villalba, 2010; Gutiérrez Barrenengoa, 2012; Ramos Domínguez, 2011). 
Pese al indudable rol instrumental de la HC respecto a la prestación de asistencia médica, así como su trascendencia probatoria frente a reclamos judiciales por mala praxis, con frecuencia se advierten deficiencias en su confección y conservación. Estas deficiencias constituyen una fuente de riesgos médicos para la salud del paciente y de riesgos legales para los profesionales de la salud. Estos últimos pueden generar consecuencias jurídicas en los ámbitos administrativo, laboral, civil y penal. En suma, pueden dar lugar a procesos en los que, como resultado, se dispongan sanciones pecuniarias, disciplinarias o penales, como la inhabilitación profesional y hasta la privación de libertad del personal de la salud.

Una mirada a la producción científica internacional que tiene a la HC como objeto de estudio nos permite advertir la existencia de un abundante patrimonio bibliográfico en torno a ella. En este ámbito figuran publicaciones sobre su estructura y contenido, su gestión electrónica y documental, así como su valor probatorio (Gutiérrez Barrenengoa, 2012; Heredia Boada, 2015; Lombana Villalba, 2010; Salazar Santafe, 2017; Silvia Velito y Tejada Soriano, 2010; Siso Martín, 2017; Herrán Ortiz, 2012; Hernández Salvador, 2004). Concretamente, sobre la forma de evaluar el riesgo médico-legal de este instrumento médico, destaca el score de riesgo diseñado por el Dr. Valenti (2017), que por su sencillez y utilidad constituye un referente con tales propósitos. De igual forma, porque puede ser fácilmente ajustado a la realidad contextual en la que se desarrollan los servicios de salud en las diferentes instituciones médicas.

En pleno contraste, resultado de la búsqueda realizada en las principales revistas jurídicas de nuestro país no encontramos ninguna publicación cuyo centro de atención haya sido el alcance y valor probatorio de la historia clínica. Esto denota que la temática ha estado alejada del debate doctrinal en nuestro escenario académico. De la misma forma, salvo una investigación realizada por Uzoatuegwu Roblejo (2019) en el Hospital Materno Sur Mariana Grajales de Santiago de Cuba, no hemos hallado otros estudios que aborden cómo evaluar el riesgo médico-legal de la HC. Esta situación tiene su reflejo en el vago orden normativo que se refiere a este instrumento médico. En este tenor, ni la ley marco para los servicios de salud -Ley 41 (1983)- ni su reglamento -Decreto 139 (1988)- la mencionan. Es en el Reglamento General para el funcionamiento de los Hospitales (Resolución 1, 2007), donde se comprenden varios aspectos respecto a sus características, uso y cuidado. Sin embargo, esta constituye una norma de inferior jerarquía y limitado alcance porque sus disposiciones, en principio, solo tienen carácter vinculante para los hospitales, que no son la única institución de salud en el país.

Con arreglo a lo expuesto, este artículo persigue como propósito principal analizar el alcance y valor probatorio de la $\mathrm{HC}$ en el ámbito jurídico-procesal, a la luz del ordenamiento jurídico cubano frente a la discutida definición de su carácter de documento público o privado. Además, se plantea como objetivo secundario, enunciar 
aquellos factores que constituyen riesgos legales asociados a la HC e inciden en su valor probatorio. Connotar esta discusión científica resulta imprescindible en el actual escenario en el que se manifiesta un aumento de los juicios por responsabilidad médica, ya que la $\mathrm{HC}$ es una de las evidencias con más relevancia en este tipo de procesos.

El texto destaca la trascendencia jurídica probatoria de la HC y la importancia de una adecuada gestión de los riesgos asociados a su manejo conforme a la lex artis que dinamiza la relación médico-paciente. También se muestra el comportamiento del estado del arte del tema en el país y las falencias legales en este aspecto. La metodología seguida estuvo sustentada fundamentalmente en los métodos analítico-sintético, inductivo-deductivo y el hermenéutico. En correspondencia con ello, la indagación es de tipo documental, argumentativa y exploratoria, pues parte de conceptos desarrollados por la ciencia jurídica, la normatividad y la jurisprudencia.

\section{LA HISTORIA CLÍNICA ¿DOCUMENTO MÉDICO O JURÍDICO? ALCANCE Y VALOR PROBATORIO}

La voz documento tiene su etimología en el latín documentum, derivado del verbo docere que significa: enseñar, instruir, mostrar, dar a conocer o informar (Cruz Mundet, 2011; Mantecón Ramos, 2014). La Real Academia Española (2020) lo define como un escrito que proporciona información fiable o que puede ser empleado para probar algo. De esta noción filológica surgen dos interpretaciones que han generado discusión sobre el tema. Por un lado, documento es algo escrito, lo cual constituye una visión en extremo limitada y, por otro lado, este concepto debe tener una interpretación mucho más amplia, pues puede ser todo aquello que sirva para probar algo. Si la primera definición, para algunos autores, peca de reduccionista, la segunda pudiera considerarse demasiado amplia a tal punto que prácticamente todo o casi todo, siempre y cuando sirva para probar, sería documento (Chiovenda, 1925; Martín Hernández, 2000; Parra Quijano, 2007).

No obstante, desde hace varias décadas se ha superado el concepto en su visión más tradicional o restrictiva. En este sentido, por documento habría que entender, además del papel, todo soporte a través del cual se registra una manifestación del pensamiento que perdura en el tiempo. Así, por ejemplo, una cinta magnetofónica o $\mathrm{CD}$, las fotografías, copias fotostáticas y los registros dactiloscópicos (Sada Contreras, 2000). Incluso, con el desarrollo de las tecnologías de la información y de las comunicaciones, actualmente es común hablar de los llamados documentos electrónicos (informáticos y virtuales).

En este sentido, con la aprobación de la Ley Modelo de la Cnudmi sobre Comercio Electrónico (1996), adecuada y adoptada por la mayoría de los países miembros de la Organización de las Naciones Unidas (1999), al advertir que un grupo importante de transacciones comerciales internacionales se realizaban por medio del intercambio 
electrónico de datos, se otorgó reconocimiento jurídico a los "mensajes de datos"1 como método de comunicación y almacenamiento de información sustitutivo de los que utilizan papel (Naciones Unidas, 1999). En efecto, se consideran documentos, en sentido amplio, a todos aquellos medios que, con independencia de su materialidad, poseen capacidad para contener información duradera, susceptible de consulta y que, por ello, pueden ser empleados como fuente de prueba (Parra Quijano, 2007; Sada Contreras, 2000; Walne, 1988).

De acuerdo con lo anterior, el soporte, la información y el registro, son los principales elementos que definen al documento. En primer lugar, el soporte le confiere la capacidad que posibilita que la información que contengan sea accesible para su ulterior consulta; en segundo lugar, la información constituye su razón de ser; finalmente, el registro distingue la forma en que la información se fija en el soporte, ya sea mediante tinta, impulsos electromagnéticos u otro cualquiera (Cruz Mundet, 2011). En síntesis: "Un documento es información registrada producida o recibida en la iniciación, desarrollo o finalización de una actividad institucional o individual y que consta de contenido, contexto y estructura suficiente para proporcionar prueba de la actividad" (Committee on Electronic Records, 1997, p. 22).

Por otro lado, los siguientes aspectos vienen a ser componentes determinantes de los documentos: contenido, estructura, contexto y presentación. El contenido se refiere al mensaje que conserva (dato o información); la estructura se refiere a la utilización de encabezamientos y acápites que ilustran las partes del documento; el contexto es el medio en el que el documento se crea y utiliza; y la presentación revela la forma en la que se muestra el contenido y la estructura (Cruz Mundet, 2011).

Otro aspecto de relevancia, en relación con los documentos, responde al valor primario y secundario que estos poseen de cara al tráfico socio-jurídico como propiedad que le es inherente. El valor primario tiene lugar desde su creación y precisamente se relaciona con en el motivo que los origina. El valor secundario, histórico o permanente, depende de la utilidad que de ellos pueda derivar posteriormente, sobre todo como fuente para la investigación. Al mismo tiempo, no es de extrañar que los documentos también gocen de un valor paralelo: el valor legal, jurídico o probatorio, muy asociado a su contenido y al resto de sus componentes (estructura, contexto y presentación). De ahí la afirmación según la cual todo documento puede tener un valor legal aunque no revele en su contenido un asunto estrictamente jurídico (Cruz Mundet, 2011).

Conviene ahora contestar la pregunta que opera como título de este apartado: ¿La historia clínica es un documento médico o jurídico? En aras de buscar la respuesta correcta, debemos partir de la precisión del valor primario de la HC, es decir, aquel

"Por 'mensaje de datos' se entenderá la información generada, enviada, recibida o archivada o comunicada por medios electrónicos, ópticos o similares, como pudieran ser, entre otros, el intercambio electrónico de datos (EDI), el correo electrónico, el telegrama, el télex o el telefax" (Naciones Unidas, 1999, p. 4). 
valor que nace con su creación y, además, se relaciona con en el motivo que la origina. En este sentido, como señalan Castellano Arroyo y Gisbert Calabuig (2005): "La historia clínica surgió como un documento en el que el médico manuscribía todos los datos derivados de la entrevista y la exploración del paciente, para asegurar un seguimiento evolutivo" (p. 102), y así ha trascendido hasta la actualidad. En razón a ello, la HC constituye un documento médico que surge de dicha práctica (Silvia Velito y Tejada Soriano, 2010). Su origen funcional, como instrumento destinado a la labor asistencial, es lo que define su naturaleza primigenia y valor primario y no los usos secundarios que pueda tener en determinadas circunstancias. Al ser pilar básico de esta actividad no hay duda de que su función principal "es la clínico-asistencial y deriva del motivo por el que se genera: la necesidad de tener agrupada toda la información sobre una persona, necesaria para el tratamiento o prevención de la enfermedad" (Herrán Ortiz, 2012, p. 98).

Es cierto que la historia clínica tiene o podría tener implicaciones jurídicas como evidencia o fuente de prueba, pero ese es un valor inherente a todos los documentos que devienen en documento archivístico (Mena Mugica, 2014). Sin embargo, ante el incremento de reclamaciones en los diferentes ámbitos jurisdiccionales, incluido el penal, por presuntas malas praxis médicas (Jericó Ojer, 2018), resulta fuente de prueba esencial, destacándose así su valor jurídico probatorio.

En palabras de Maier (1996): "En general, llamamos prueba a todo aquello que, en el procedimiento, representa el esfuerzo por incorporar los rastros o señales que conducen al conocimiento cierto o probable de su objeto" (pp. 858-859). Así, desde la perspectiva jurídica-procesal: "Probar significa convencer al juez sobre la certeza de la existencia de un hecho" (Roxin, 2003, p. 185). De ahí la importancia del correcto desenvolvimiento de la intitulada, en los predios del derecho procesal, como actividad probatoria. Esta no es más que la "actividad de las partes destinada a producir en el juez la certeza de que los hechos que han alegado son ciertos" (Martín Hernández, 2000, p. 120). Por tanto, "el móvil que debe estimular la actividad probatoria [... no no otro que el de llevar probanzas que presten algún servicio en el proceso para la convicción del juez" (Parra Quijano, 2007, p. 156). En el mismo sentido, pero refriéndose al proceso penal, Arranz Castillero (2003) sostiene que dicha actividad tiene como propósito "que el órgano jurisdiccional adquiera la certeza plena y fundamentada sobre la hipótesis inculpatoria que conlleva la aplicación de la ley penal sustantiva, o en su defecto, asuma una opinión exculpatoria y se pronuncie consecuentemente a favor del reo" (p. 26).

Un momento de importancia toral en el marco de la actividad probatoria es aquel en el que corresponde realizar la valoración de la prueba. Nieva Fenoll (2010) define esta práctica como la "actividad de percepción por parte del juez de los resultados de la actividad probatoria que se realiza en un proceso" (p. 34). En esta misma línea, según Taruffo (2008), este paso significa "determinar el valor 
probatorio de cada medio de prueba en relación con un hecho específico, y tiene por objeto establecer cuando y en qué grado puede ser considerado verdadero [...] el enunciado que afirma la ocurrencia de ese hecho" (p. 139).

Frente a esta actividad, la prueba documental, también llamada instrumental y por algunos autores literal (Sada Contreras, 2000), es el medio probatorio que el derecho procesal concibe para lograr el ingreso al proceso del elemento de prueba que se encuentra registrado en un documento (Cafferata Nores, 1994). Su regulación legal permite que el dato probatorio existente fuera del proceso penetre en él para ser conocido por el tribunal y las partes. Esta regulación se materializa, según su propio nombre, en documentos, conforme al concepto amplio que hemos asumido ut supra. Así, la importancia del documento como prueba obedece a la fuerza demostrativa que lo caracteriza y a la fidelidad con la que, por lo general, acreditan hechos, datos o acontecimientos relativos al tráfico jurídico o situaciones comunes de la vida que terminan ventilándose en un litigio (Mantecón Ramos, 2014).

En armonía con lo indicado, la HC reúne condiciones que la hacen codiciable como fuente de prueba. Entre ellas, el carácter descriptivo de las anotaciones, y aglutinador, de las distintas atenciones y exámenes realizados al paciente. También refuerzan su valor probatorio, el rigor científico que la debe identificar y la presunción de veracidad de cuanto contiene (García Millán, 2019; Siso Martín, 2017). Una HC bien elaborada siempre contendrá aquellos criterios de opinión, estudio y valoración de los profesionales que han intervenido en la asistencia al paciente. Además, su confección se desarrolla a medida que ocurren los acontecimientos que involucran al paciente y ese registro ordenado de aconteceres facilitará luego, a quien la analice, discernir con claridad la calidad asistencial ante posibles reclamos por responsabilidad profesional.

En efecto, en los casos en los que se pretenda presentar un reclamo de responsabilidad médica derivada de una mala praxis, la necesidad de acceso a la HC viene motivada porque el relato de los hechos, así como la individualización del presunto responsable, estarán directamente relacionados con la secuencia de datos relativas al diagnóstico, tratamiento, etc., reflejadas en ella por los facultativos actuantes o, según los casos, las omisiones en que estos incurrieron (Rives Seva, 2004).

No obstante, desde la perspectiva jurídica procesal, la $\mathrm{HC}$ no es un medio de prueba en sí, sino que constituye un documento médico que porta elementos de prueba. En otras palabras, la $\mathrm{HC}$ es un conjunto de datos objetivos que se podrán incorporar legalmente al proceso, capaz de producir un conocimiento cierto o probable sobre los aspectos íntimamente ligados a la pretensión de las partes en el proceso civil y acerca de los extremos de la imputación delictiva en un proceso penal (Lombana Villalba, 2010; Cafferata Nores, 1994). Ahora bien, su ingreso al proceso requiere de su legitimación a través del correspondiente medio de prueba, que en este caso sería la prueba documental. Es precisamente cuando se anexa a las actuaciones para su 
valoración por el Tribunal que la HC ingresa a este sector del tráfico jurídico, de esta manera, el documento médico adquiere el carácter de prueba documental. Así, en este contexto, la HC estará destinada a la verificación de aquellos aspectos directamente relacionados con la determinación de si con la conducta médica, apegada o no a las exigencias de la lex artis, se creó un riesgo no permitido para la vida o la salud del paciente. Asimismo, de acuerdo con las anotaciones de la HC, quizá pueda determinarse si la conducta médica, generadora del riesgo jurídicamente desaprobado, dio lugar al resultado de lesión o muerte al paciente.

Todos los datos que contienen las historias clínicas, incluso aquellos no relacionados directamente con el problema o la cuestión clínica, poseen la misma relevancia a efectos de determinar la responsabilidad legal del médico. De ahí que todo cuidado es poco al momento de la conformación, uso y conservación de este documento médico. Como se ha ilustrado, este documento puede devenir en fuente de prueba para evidenciar una posible mala práctica médica, pero también constituye el mejor medio de defensa para demostrar la inexactitud de las bases de la demanda o denuncia. De esta manera, permite, en su caso, desvirtuar la pretensión del demandante o los argumentos incriminatorios que se presenten en una acusación.

Ahora bien, que la $\mathrm{HC}$ tenga un valor probatorio trascendental en procesos de mala praxis no significa que dicho valor sea absoluto. En este sentido, la HC no se considera la prueba reina o tasada (Gutiérrez Barrenengoa, 2012; Mantecón Ramos, 2014; Martín Hernández, 2000). Aunque contiene la memoria sobre la situación y evolución clínica del paciente, desde su ingreso al centro asistencial, no constituye toda la documentación existente en los centros de salud respecto a este. Ello sin señalar aquellos supuestos en que su valor probatorio se ve afectado por la presencia de enmiendas, tachaduras, incongruencias, entre otras irregularidades, que dan viso de su deficiente elaboración. Estos defectos inciden en su eficacia probatoria. Además, tampoco es aconsejable inadvertir que quien aporta la $\mathrm{HC}$, una vez solicitada por la autoridad competente, es la misma institución o profesional de la salud a quién va a perjudicar o favorecer.

En todo caso, en lo que supone una clara aplicación de la denominada doctrina de la valoración conjunta de la prueba, no debe tomarse en consideración a la HC como si se tratase de un medio probatorio definitivo. Considerarla de ese modo implicaría una valoración legal de su contenido en perjuicio del resto del material probatorio que pudiera conducir a supuestos de responsabilidad objetiva. A contrario sensu, ha de ser puesta en relación con las restantes pruebas practicadas en el proceso de cara a la obtención de una conclusión por parte del juzgador. Es un principio universalmente reconocido que los Tribunales deben valorar las pruebas en su totalidad, tomando en consideración todos y cada uno de los medios de prueba presentados en el procedimiento (Larena Beldarraín, 2012). 
Derivado de estas máximas, a pesar de sus características y trascendencia en el marco de la relación médico-paciente, los datos que en ella se incluyen pueden y deben estar sujetos a verificación. Incluso, "siempre" se podrá determinar la responsabilidad médica a la luz de otros elementos y medios de prueba, que también pueden entrar en contradicción con los datos que en ella se registran. Si bien se reconoce la relevancia de la $\mathrm{HC}$ en procesos motivados por responsabilidad profesional médica, su valor como fuente de prueba habrá de confrontarse con el resto de los medios probatorios: informes periciales, declaración de testigos, o cualquier otro documento aportado como medio de prueba al proceso (García Millán, 2019). Como se sabe, las pruebas documentales pueden ser susceptibles de peritajes para verificar o conocer nuevos elementos en torno a lo sucedido, por ejemplo, puede peritarse la HC para verificar el autor de algún fragmento de texto escrito en ella, lo cual sería una prueba pericial realizada a una documental.

De todas formas, en la fijación de la fuerza probatoria de un documento siempre influirá el carácter de público o privado que este tenga. En este sentido, se le confiere mayor fuerza demostrativa al documento público que al privado. Los documentos públicos suelen tener a su favor una presunción de autenticidad a tenor de las medidas que encierran su producción, en tanto los privados, por lo general, requieren ser convalidados. No obstante, para que el documento tenga fuerza probatoria, en todos los casos debe ser auténtico. En palabras de Cruz Mundet (2011), auténtico es el documento que puede probar que: (1) es lo que pretende ser; (2) ha sido creado o enviado por la persona que se presume; y (3) ha sido creado o enviado en el tiempo presumido.

Sobre esta cuestión, nuestra Ley de Procedimiento Civil, Administrativo, Laboral y Económico (Lpcale) establece en su artículo 294 que:

Los documentos otorgados con la intervención de funcionario público con las formalidades legales, harán prueba plena entre las partes que en ellos hayan figurado, respecto a las declaraciones que contengan o que de ellas inmediatamente se deriven. Harán prueba asimismo, aún respecto a terceros, en cuanto a su fecha y al motivo de su otorgamiento. (Ley 7, 1977)

La fuerza probatoria del documento público también se prevé en el artículo 1.218 del Código Civil (1889) español, según el cual: "Los documentos públicos hacen prueba, aun contra tercero, del hecho que motiva su otorgamiento y de la fecha de este" (Real Decreto, 1889). Asimismo, la Ley 1 (2000), del 7 de enero, o Ley de Enjuiciamiento Civil, en su artículo 319, relativo a la fuerza probatoria de los documentos públicos, establece que "harán prueba plena del hecho, acto o estado de cosas que documenten, de la fecha en que se produce esa documentación y de la identidad de los fedatarios y demás personas que, en su caso, intervengan en ella" (Ley 1, 2000). 
Como se aprecia, en ambos ordenamientos jurídicos del tenor literal de los citados preceptos, el documento público deviene, en principio, en prueba tasada. Es decir, vincula al juez en relación con los hechos o datos que contiene, esencialmente en lo que se refiere a su contenido dispositivo (valor intrínseco). En este sentido, la importancia y utilidad de los documentos públicos radica en la posibilidad que tienen para acreditar de forma categórica aspectos como la autoría, fecha de emisión y todas aquellas circunstancias que han contribuido a su formación (Nieva Fenoll, 2017; Serra Domínguez, 2009). Es por ello, que en el reino español, por ejemplo, se ha querido reforzar el alcance probatorio de la HC otorgándole el carácter de documento público cuando ha sido fruto de la labor del personal médico de las instituciones estatales de salud. Esta postura ha tenido profundos razonamientos en sede judicial como lo ilustra la Sentencia 84 (2006) de la Sala Primera de lo Civil del Tribunal Supremo de España.

En el proceso penal cubano, por su parte, rige el modelo de libre valoración de la prueba guiado por las reglas de la sana crítica y no existen excepciones o rezagos de prueba tasada, como ocurre en sede civil en relación con la confesión judicial y -con algunos matices- a los documentos públicos. Ello no significa que en sede penal deje de tener relevancia, a efectos probatorios, la diferencia existente entre el carácter público o privado de los documentos en torno a la presunción de autenticidad que por regla general se otorga a los de carácter público. Además, en el ámbito sustantivo del derecho penal la distinción entre el carácter de los documentos cobra especial importancia toda vez que de ella depende la tipificación de un delito de falsificación de documentos públicos o de falsificación de documentos privados, previstos y sancionados en los artículos 250 y 257 del Código Penal (Ley 62, 1987). En este tenor, bien pudiera acontecer un proceso en el que junto a la mala praxis médica exista un delito de falsificación en relación de conexidad sustantiva o procesal. Por tanto, conforme a lo expuesto, estimamos necesario valorar el carácter público o privado de la HC y argumentar la postura que juzgamos pertinente según nuestro esquema legal. A esto nos dedicaremos en el siguiente apartado.

\section{2. ¿CONSTITUYE LA HISTORIA CLÍNICA UN DOCUMENTO PÚBLICO O PRIVADO?}

La HC, tal cual hemos asumido, es el conjunto documental en el que se refleja el proceso de evolución del paciente desde la aparición de la enfermedad hasta que recibe el alta médica. En ella se reflejan todos los datos alusivos al tratamiento prescrito, exploraciones realizadas, etc.; además, en ella se recogen otros instrumentos informativos como es el caso de los análisis o radiografías efectuados. Constituye, por tanto, la documentación de la evolución clínica del paciente, y su importancia reside en el hecho de que en ella aparecen las incidencias más relevantes acaecidas durante el tratamiento, control y seguimiento médico realizado. En esa medida, también incorpora toda aquella información que se haya proporcionado de manera verbal. 
Según el fin por el cual la HC ha sido creada no hay lugar a duda de que se trata de documentación clínica, aunque conforme a la generalidad de los documentos también comporta como valor paralelo, el valor legal, jurídico o probatorio. No obstante, si tenemos en cuenta el detalle con que, en general, deben ser elaboradas -tanto en lo referente a las medidas adoptadas en cada caso como al momento en que estas son ejecutadas- podemos afirmar sin ambages que, en multitud de ocasiones, devenida en prueba documental constituye prácticamente el único elemento del que se dispone para llevar a cabo la reconstrucción de los hechos acontecidos. Sin embargo, aunque existe consenso en la doctrina sobre este aspecto, para una mejor inteligencia de la problemática probatoria que la envuelve resulta obligatorio hacer un análisis de su clasificación como documento público o privado. Este análisis también debe hacerse sobre aquellos supuestos en que constituye el corpus delicti en relación con las falsedades documentarias.

En términos generales, la doctrina sostiene que la característica fundamental que diferencia documentos públicos y privados, radica en que en la elaboración de los primeros interviene un notario o funcionario al que la ley confiere la fe pública (Martín Hernández, 2000). Así, los documentos que son librados por funcionarios competentes para ello, en cumplimiento de sus funciones y con las solemnidades establecidas en ley, adquieren la cualidad de documento público y se les atribuye mayor fuerza demostrativa. Del mismo tenor de esta definición, resulta que no todos los documentos emitidos por funcionarios son documentos públicos porque deben concurrir las solemnidades y exigencias requeridas por la ley para su formación.

A contrario sensu, la elaboración de los documentos privados, como su nombre lo indica, tiene lugar sin la intervención de fedatario público que acredite su autenticidad y, por ello, poseen menor eficacia en el orden probatorio que los documentos públicos (Martín Hernández, 2000). Visto así, el concepto de documentos privados ostenta un carácter residual, a él se llega por exclusión y tienen tal carácter todos aquellos que no sean públicos (Chiovenda, 1925; Mantecón Ramos, 2014; Martín Hernández, 2000; Sada Contreras, 2000). En consecuencia, como bien sostiene Martín Hernández (2000): "Esta distinción entre documento público y privado desempeña un papel fundamental. Mientras que los públicos prueban por sí mismos, documentalmente, su autenticidad, la de los privados hay que probarla" (p. 137).

Esta postura doctrinal es asumida generalmente en los ordenamientos jurídicos nacionales. El legislador español, por ejemplo, en el artículo 1.216 del Código Civil (1889) considera como documentos públicos "los autorizados por un notario o empleado público competente, con las solemnidades requeridas por la ley" (Real Decreto, 1889) y, por exclusión, el resto de los documentos que sean parte del tráfico jurídico se reputarán como privados (García Millán, 2019). 
En Cuba, a diferencia de lo previsto en sede civil, ni la ley sustantiva penal ni la procesal especifican las características de los documentos de modo que permitan una correcta y uniforme identificación según su carácter de público o privado. Esta indefinición, en palabras de Pérez Pérez (2003), provocó confusión en la práctica judicial en sede penal que ante el vacío conllevó a que el Consejo de Gobierno del Tribunal Supremo Popular dictara la Instrucción $108(1983)^{2}$. En ella se estableció que tendrían la condición de documentos públicos, a los efectos del delito que penaliza su falsificación ${ }^{3}$, aquellos que cumplieran las exigencias previstas en el artículo 281 de la entonces Ley de Procedimiento Civil, Administrativo y Laboral (1977), conocida actualmente como Lpcale (Instrucción 108, 1983). Este precepto jurídico reconoce como documentos públicos:

1) los autorizados por funcionarios público competente con las formalidades requeridas por la ley; 2) las certificaciones de dichos documentos expedidas en forma legal; 3) los Registros oficiales y las certificaciones de los asientos que obren en los mismos expedidos por los funcionarios que los tuvieren a su cargo; 4) las actuaciones judiciales y las certificaciones legalmente expedidas con vista de las mismas. (Ley 7, 1977; Instrucción 108, 1983)

Según la propia Instrucción 108 (1983), por costumbre, la legislación procesal civil ha sido la encargada de regular lo referido a los medios de prueba con valor extensivo a las restantes ramas del derecho. Por tanto, todos los tribunales -incluidos los de lo penal-a los efectos de establecer la categoría de los documentos involucrados en una decisión judicial de su competencia, deben remitirse a lo que sobre ello se ha dispuesto en el ordenamiento jurídico-civil. De tal forma, no quedó a la discrecionalidad de los tribunales, con los riesgos que a ello se le atribuye, la precisión del carácter público o privado de los documentos.

Sin embargo, a pesar de que en el ordenamiento jurídico civil se relacionan genéricamente los documentos que se consideran de carácter público y ello resulta extensivo al ámbito penal, en su aplicación se generaron dudas que exigieron la emisión del Dictamen 162 (1983) del Consejo de Gobierno del Tribunal Supremo. Sobre todo, en lo relativo a la definición de funcionarios públicos para, de conformidad con el carácter de funcionario que los emite, poder determinar si el documento es público o no. En este sentido, el dicho dictamen reiteraba ampliamente la manera en que los tribunales del fuero penal deberían interpretar el mencionado artículo, en los siguientes términos:

En el artículo 281 de la Ley de Procedimiento Civil, Administrativo y Laboral se relacionan, genéricamente, los documentos a los cuales dicha legislación considera

2 Así se expresa en uno de los por cuantos de la referida Instrucción que: "Esta indefinición ha provocado una gran confusión en la práctica judicial y ha dado lugar a que sean frecuentes los casos en que sentencias de los Tribunales Provinciales Populares deban ser casadas por haberse incurrido en error en ellas en cuanto al carácter atribuido al documento en que se funda la calificación" (Instrucción 108, 1983).

3 Este artículo fue modificado por la Ley 62 (1987) vigente hasta hoy, manteniéndose bajo el numeral 250 (Rivero García y Bertot Yero, 2013). 
de carácter público. En el inciso primero del mencionado artículo se expresa que tienen esa categoría "los autorizados por funcionario público competente con las formalidades requeridas en la Ley". De lo expuesto se advierte que la ley no formula una relación nominal de tales documentos, sino que enumera los requisitos que debe reunir un documento para ser calificado de carácter público.

En consecuencia, la primera cuestión a dilucidar es conocer si quien emite el documento es o no un funcionario público, para ello nos apoyamos en la disposición complementaria al título II del Libro II del Código Penal (1979), artículo $194,{ }^{4}$ que textualmente dice: "a los efectos de este Título se entiende por funcionario público toda persona que tenga funciones de dirección o que ocupe un cargo que implique responsabilidad de custodia, conservación o vigilancia en Organismo Público, Institución Militar, Oficina del Estado, Empresa o Unidad de Producción de Servicio".

En segundo término será necesario conocer si el documento subscrito por el funcionario público está dentro del ámbito de su competencia, esto es, si tiene facultad para realizar ese acto.

No menos importante será comprobar si el documento fue expedido de acuerdo con los requisitos legales exigidos para su fehacencia [sic].

También será necesario analizar su contenido, es decir, si tiene por objetivo una declaración de voluntad reconociendo, negando, modificando, una relación jurídica o es fiel expresión de un estado o situación de fecho [sic] con relieve jurídico.

De lo expresado se advierte que resulta materialmente imposible confeccionar una relación nominal de los documentos considerados de carácter público, por las varias especies existentes y la dinámica que surge en las relaciones jurídicas, en una sociedad en constante transformación.

Tienen el carácter de documento público, entre otros, aquéllos que reúnan los requisitos establecidos en el artículo 281, inciso primero, de la Ley de Procedimiento Civil, Administrativo y Laboral, atendiendo a la persona que lo emite, al ámbito de sus facultades, al cumplimiento de los requisitos formales de carácter legal y finalmente al contenido del mismo. (Dictamen 162, 1983)

Hasta aquí es posible concluir que la condición de documento público, en términos generales, depende de la evaluación de tres aspectos fundamentales relativos a su proceso de formación: (1) el ámbito en que se origina; (2) el sujeto u órgano del cual proviene su elaboración, sea que este opere como creador de todo el documento o lo haga para otorgarle autenticidad en su condición de funcionario público depositario de la fe pública, ya sea notarial, administrativa o judicial; y (3) el cumplimiento de las formalidades legales, expresión de la autenticidad oficial que los presenta como veraces (Mejías Rodríguez, 2012).

4 Este artículo fue modificado por la Ley 62 (1987), manteniéndose en la actualidad bajo el numeral 173 (Rivero García y Bertot Yero, 2013). 
Ahora bien, aunque en el ámbito del proceso civil están definidas las pautas para establecer la distinción, en la práctica algunos de los problemas que pueden presentarse en el manejo de la prueba documental se asocian, por lo común -incluso en este propio ámbito- a la correcta clasificación de los documentos (Mantecón Ramos, 2014). Siempre surgirán dificultades, generadas por la duda, al momento de encuadrar, en cada caso, los requisitos que debe reunir un documento para ser calificado como público. Téngase en cuenta que, como señala Mantecón Ramos (2014), el modelo procesal cubano adolece de una definición acabada de funcionario público. También se observa en la práctica una tendencia a proponer la prueba documental en sede civil sin distinguir la naturaleza del documento. Ello constituye, como significa ese propio autor, un proceder impropio, ya que la proposición de la prueba en este ámbito ha de apegarse a los criterios técnicos que preordenan la materia; máxime en supuestos como este en los que tal distinción trasciende al modelo de valoración que se instituye.

Realizadas estas precisiones teóricas y normativas, la respuesta al interrogante de si la HC elaborada en el seno de las instituciones de nuestro Sistema Nacional de Salud adquiere el carácter de documento público o privado, va a depender obviamente del cumplimiento de los requisitos señalados. Bajo esta referencia, hemos de concluir que la $\mathrm{HC}$ no tiene encaje en ninguno de los supuestos del artículo 281 de la Lpcale (1977). En primer lugar, la misma no está elaborada con la finalidad de dar fe pública y su redacción es llevada a cabo por profesionales que no ejercen funciones de imperium. Su finalidad o valor primario es garantizar la calidad de asistencia médica conforme a la lex artis, aunque por sus valores intrínsecos (entidad productora, orígenes funcionales, fecha y lugar de producción, contenido sustantivo) tenga utilidad como fuente de prueba de los datos que contiene.

Llama la atención que en el orden normativo, ni la ley marco para los servicios de salud en Cuba (Ley 41, 1983) ni su reglamento (Decreto 139, 1988) se refieren a la HC, a pesar de su importancia en la labor asistencial. Es en el Reglamento General para el funcionamiento de los Hospitales (Resolución 1, 2007), donde se comprenden varios aspectos respecto a sus características, uso y cuidado. Sin embargo, esta constituye una norma de inferior jerarquía y limitado alcance porque sus disposiciones, en principio, solo tienen carácter vinculante para los hospitales, y estas no son las únicas instituciones de salud en el país. Otras regulaciones del Ministerio de Salud Pública de Cuba (Minsap), se refieren a la HC como un documento de trabajo limitándose prácticamente a su definición, por ejemplo, el Reglamento General de Policlínico (Resolución 135 , 2008). En este sentido, consideramos loable que sin pretender importar modelos, se examinen experiencias foráneas que revelan una adecuada configuración del marco regulador para el tratamiento de la información y la documentación clínica. Tal es el caso en el reino español de la "Ley 41/2002, de 14 de noviembre, básica reguladora de la autonomía del paciente y de derechos y obligaciones en materia de información y documentación clínica" (Ley 41, 2002). 
En el Reglamento General para el funcionamiento de los Hospitales (Resolución 1 , 2007) se define la HC como el conjunto de documentos que recogen toda la información de la atención médica brindada al paciente y establece que se mantendrá una para cada paciente, independientemente del número de ingresos del cual sea sujeto. Además, es el documento con el que se inicia y donde se registra la atención médica integral, tanto durante la hospitalización como en la atención ambulatoria. De igual modo, se exige que sea escrita con la letra clara y legible, e indica que el contenido y ordenamiento estarán regulados de acuerdo con las características de cada especialidad. Pero en todos los casos debe asegurarse una HC completa, actualizada, firmada de manera adecuada y acuñada por las diferentes personas que participen en la atención del enfermo.

También se reglamenta que los datos contenidos en el expediente clínico, además del uso médico, tendrán valor científico, académico y legal, y todo el personal del hospital está obligado a mantener reserva sobre el contenido del mismo. De esta manera, será sancionable la falta de discreción sobre estos aspectos y será el Departamento de Registros Médicos el responsable de la guarda y cuidado de la HC. Sin embargo, lo que nos resultó más interesante conforme al debate que venimos sosteniendo, es el hecho de que esta disposición administrativa en su artículo 120 le atribuye a la HC el carácter de documento público propiedad del hospital: "La Historia Clínica es el documento público propiedad del hospital por lo que se prohíbe terminantemente su extracción de la institución, a excepción de algunos casos previa autorización expresa del Director" (Resolución 1, 2007). Esta situación resulta cuestionable porque, atendiendo a la fuente emisora, la HC no reúne las exigencias que para la calificación del documento público sostiene la doctrina y refrenda el artículo 281 de la Lpcale (1977).

A tono con lo anterior, surge la cuestión de si a las historias clínicas que se producen en otras instituciones de salud -por ejemplo, policlínicos y consultorios médicos- también se le atribuye la categoría de documento público. Sin embargo, como resultado de la revisión de las disposiciones normativas reguladoras de los lineamientos generales para la organización y funcionamiento de esos centros de salud, no existe pronunciamiento alguno respecto al carácter público o privado de la HC. Por esta razón, conforme con la línea de pensamiento que hemos seguido, la interpretación correcta sería la de considerarlas como documentos privados.

Finalmente, ante la irrupción de las nuevas tecnologías de la información y la comunicación en el ámbito médico, también se plantea el reto de cara a la adecuada clasificación del carácter público o privado de la HC electrónica, con independencia de que su desarrollo en formato digital es aún incipiente en Cuba (García, 2017; Fonticoba Valdés et al., 2018; Prensa Latina, 2019). En este debate somos de la opinión que han de seguirse los mismos parámetros que se disponen en la doctrina y en el ordenamiento jurídico para los documentos en formato 
físico. Por tanto, cuando sea confeccionada una HC electrónica, de no cumplirse las exigencias establecidas en ley para la elaboración de los documentos públicos, entonces, nos encontraríamos en el entorno que caracteriza al documento privado.

En síntesis, en nuestro ordenamiento jurídico se revela una dualidad en cuanto al carácter de documento público o privado que se le puede atribuir a la $\mathrm{HC}$, según se trate de aquella confeccionada en los hospitales o se haya elaborado en otro centro de salud. Esta situación, obviamente contradictoria, debe ser de lege ferenda corregida sobre la base de la observancia del carácter privado de la HC conforme a lo establecido en la Lpcale. Lo que hoy existe, desde el punto de vista normativo, se traduce en una afectación de la seguridad jurídica frente a la fuerza probatoria que se le atribuya a la $\mathrm{HC}$ en un proceso judicial. Esto toda vez que, mientras los documentos públicos tienen a su favor una presunción de autenticidad, los privados generalmente requieren ser convalidados. También tiene incidencia en la correcta y justa tipificación de las falsedades documentales, que reprime la legislación sustantiva penal, pues se tipifican diferentes figuras de delito según el objeto de la falsificación sea considerado un documento público o privado.

\section{FACTORES QUE CONSTITUYEN RIESGOS LEGALES DE LA HISTORIA CLÍNICA FRENTE A SU VALOR PROBATORIO}

La asistencia médica constituye una actividad compleja que se desarrolla en un entorno cada vez más tecnificado en el que intervienen varios profesionales de la medicina para dar solución a un problema de salud del paciente. En este contexto, con mayor razón, resulta imprescindible que se registren las actuaciones médicas realizadas por los facultativos para su oportuna consulta, en función de asegurar la calidad de la atención del paciente. La HC es la herramienta que cumple con esta función, ya que presenta el testimonio de la relación médico-paciente, pues debe contener todas las actuaciones sanitarias realizadas y los datos relativos a su salud. No en vano, su principal finalidad es la de garantizar la asistencia sanitaria, a la que se suma su utilidad en docencia, investigación, calidad asistencial, salud pública, e incluso para posibles fines judiciales, conservándose más allá del plazo del último proceso de alta del paciente (García Millán, 2019; Silvia Velito y Tejada Soriano, 2010).

La evolución científica y tecnológica experimentada por la medicina en las últimas décadas, como es de suponer, también ha tenido sus impactos en la HC. Esta, como herramienta de la labor asistencial, ha acompañado las modificaciones organizativas, administrativas y culturales sufridas por la asistencia médica. La intervención sucesiva o simultánea de varios especialistas en la atención al paciente, la frecuencia de las consultas y de los exámenes complementarios que habitualmente se le realizan, entre otras razones, han generado HC complejas e integradas por cuantiosos documentos (Castellano Arroyo y Gisbert Calabuig, 2005). 
Por otro lado, las dinámicas que impone la sociedad de la información nos aportan experiencias de su gestión en formato electrónico. Sin embargo, con independencia del soporte, siempre deberá contener el relato preciso, puntual, cronológico y fiel de cada una de las circunstancias acaecidas con el paciente. De ello depende, en gran medida, garantizar una asistencia adecuada, al asegurar el conocimiento exacto y actualizado del estado de salud del paciente y de los tratamientos recibidos por parte de los galenos que le atienden. En este tenor, siempre habrá que cuidar que la HC contenga información veraz, confiable, integra y accesible. De lo contrario, los juicios, reflexiones, cálculos, estimaciones y otras decisiones que se fundamenten en su contenido podrían ser errados, y esto puede dar lugar a algún evento adverso.

Lo anterior justifica que la HC constituya objeto de la pericia médica en los procesos incoados por presuntas malas prácticas de los profesionales de la salud. Este documento resulta un elemento clave en la elaboración de los informes medicolegales practicados por los peritos que serán apreciados judicialmente por el juez con el objetivo de determinar, primero, una relación de causalidad o no en la responsabilidad médica profesional y, segundo, un juicio de imputación objetiva y subjetiva.

No existen reparos al reconocer que la HC facilita la reconstrucción y el análisis de los actos médicos realizados en el paciente y que, por ello, es garantía de una correcta prestación médica. En palabras de Castellano Arroyo y Gisbert Calabuig (2005): "Su principal finalidad es conseguir una asistencia sanitaria de la mayor y mejor calidad a través de la coordinación de todos los profesionales que intervienen en el cuidado del paciente" (p. 102). Por otro lado, afirma Valenti (2017): "De allí su inocultable relevancia [de la $\mathrm{HC}$ ] para el diagnóstico, tratamiento, pronóstico y epidemiología, circunstancias que exigen que su confección refleje una información clara y precisa, completa y metódicamente realizada" (p. 2). En consecuencia, una HC imperfecta en su redacción, con omisiones y poca legibilidad, podría limitar notoriamente la demostración de la calidad de un acto médico como piedra angular en la exitosa gestión de la asistencia médica.

La HC como instrumento y subproducto del registro de la información de actos asistenciales permite corroborar, comprobar, analizar y evaluar todas las actuaciones médicas y, consecuentemente, se constituye en fuente de información para la identificación de riegos. A través de ella se puede conocer cómo, cuándo, por qué, para qué, dónde, por quién, etc., se realizó una actividad asistencial e identificar las implicaciones de la forma en que los mismos fueron ejecutados.

Si bien en nuestro país no existen normas jurídicas determinantes que obliguen a seguir formas especiales para la confección de la HC en general, existe un tradicional, fuerte y relativo consenso tácito entre los médicos sobre la manera de proceder en relación con su instrumentación en cada especialidad. De esta forma, el correcto registro de las actuaciones médicas con el paciente constituye parte integrante de la reconocida lex artis en este sector de actividad profesional. 
Un estudio desarrollado por Uzoatuegwu Roblejo (2019) para identificar el riesgo médico-legal presente en las historias clínicas de las pacientes en las cuales se practicó cesárea primitiva en 2017, en el Hospital Materno Sur Mariana Grajales de Santiago de Cuba, arrojó resultados inquietantes. Conforme acredita este investigador, la población objeto de estudio estuvo constituida por todas las historias clínicas de las pacientes a las cuales se les realizó parto por cesárea primitiva en el centro hospitalario durante ese año. Se seleccionaron de forma aleatoria doscientas treinta historias para constituir la muestra, donde predominaron las gestantes entre dieciocho y treinta y cinco años (ciento noventa y seis para 85,2 \%), nulíparas (ciento cuarenta y tres para 62,2 \%) y se determinó que no fueron frecuentes las complicaciones médicas en diecinueve pacientes para $18,3 \%$. Como resultado, se certifica en la investigación que poseen un riesgo medicolegal mediano ciento treinta y seis historias para 59,1\%, y alto riesgo noventa y dos historias para un $40 \%$. En este estudio, las principales dificultades se presentaron al evaluar aspectos como: orden, legibilidad, ausencia de consentimiento informado e inadecuado firmado y acuñado de la documentación. En consecuencia, se concluyó que: "Es elevado el riesgo de que las historias clínicas no puedan brindar la información necesaria para demostrar la ausencia de culpa profesional ante el desarrollo de un proceso [...] legal que evalúe praxis médica en relación a la cesárea primitiva" (Uzoatuegwu, 2019, p. 64).

A la vista de todo lo anterior, una parte importante de las deficiencias que se revelan asociadas a la confección, conservación y calidad de la HC, es resultado del escaso conocimiento que poseen los profesionales de la salud acerca del valor jurídico de este instrumento y de los riesgos legales que derivan de su inadecuada gestión. La superación de esta problemática requiere de una mayor introducción y desarrollo de estos tópicos en los currículos de las universidades médicas, así como de una mayor divulgación en el gremio médico en general, de forma tal que estos permitan una efectiva comprensión sobre las posibles consecuencias legales que pueden sufrir ante la incorrecta gestión de la HC. De igual modo, para los juristas resulta esencial no solo tener una vaga noción de la HC y sus características fundamentales, sino hacer un examen minucioso de su concepto, su evolución, sus elementos estructurantes, y su modo de elaboración. Todo esto para que los casos de responsabilidad médica frente a los cuales se encuentren actualmente tengan una solución rigurosa y correcta.

\section{CONCLUSIONES}

La HC, como conjunto documental elaborado por los profesionales de la salud durante la prestación de un servicio médico al paciente, constituye una fuente de prueba que, dadas sus características, cobra especial relevancia en los procesos seguidos por responsabilidad médica. Su justa y adecuada valoración judicial contribuye a determinar si la conducta médica, objeto de juzgamiento, se adecuó a la lex artis y, en su 
caso, posibilita probar la relación de causalidad entre la actuación médica y el daño sufrido por el paciente.

El marco normativo de las instituciones hospitalarias del Sistema Nacional de Salud del país atribuye carácter de documento público a las historias clínicas elaboradas en los hospitales, aunque en su confección no se cumplen los requisitos que para la adjudicación de tal condición se encuentran previstos en la Lpcale. Esta situación se traduce en una legitimación para preconstituir pruebas durante el ejercicio de la actividad laboral por parte de los profesionales de la salud de dichos centros asistenciales, en contravía de lo profesado sobre la distinción entre documentos públicos y privados desde nuestra ley adjetiva civil. Por tanto, resulta imprescindible de lege ferenda el perfeccionamiento del ordenamiento de salud en este sentido para evitar situaciones de privilegio.

En suma, una correcta HC -completa, ordenada, legible y actualizada-constituye una base importante en la que fundar las decisiones en materia de responsabilidad profesional. Por ello, los denominados riesgos legales tienen una importante incidencia frente a su eficacia probatoria. Una HC irregular es un fuerte indicio en contra del planteo exculpatorio del profesional actuante, en un momento en que el ejercicio médico se ha tornado complicado y sujeto a reclamos judiciales.

\section{REFERENCIAS}

Arranz Castillero, V. J. (2003). Cuestiones teóricas generales sobre la prueba en el proceso penal cubano [tesis de doctorado no publicada, Universidad de La Habana].

Asamblea Nacional de la República de Cuba. (1977, 19 de agosto). Ley 7 de 1977. Ley de Procedimiento Civil, Administrativo, Laboral y Económico. Juriscuba. http://juriscuba.com/wp-content/uploads/2015/10/ Ley-No.-007-ley-procedimiento-civil-administrativo-laboral-economico.pdf

Asamblea Nacional del Poder Popular. (1979, 3 de marzo). Ley del Código Penal. Ley 21. Imprenta Universitaria (1980).

Asamblea Nacional del Poder Popular. (1983, 13 de julio). Ley 41 de la Salud Pública. Asamblea Nacional del Poder Popular República de Cuba. http://www.parlamentocubano.gob.cu/index.php/ documento/ley-de-la-salud-publica/

Asamblea Nacional del Poder Popular. (1987, 29 de diciembre). Ley No. 62, Código Penal. Gaceta Oficial de la República de Cuba. https://www.gacetaoficial.gob.cu/es/ley-no-62-codigo-penal

Cafferata Nores, J. I. (1994). La Prueba en el Proceso Penal. Desalma.

Castellano Arroyo, M., y Gisbert Calabuig, J. A. (2005). El secreto médico. Historia clínica. Confidencialidad y otros problemas médico-legales de la documentación clínica. En, E. Villanueva Cañadas (Ed.), Medicina legal y toxicología (6. ${ }^{a}$ ed.) (pp. 93-108). Masson.

Chiovenda, J. (1925). Principios de Derecho Procesal Civil. (J. Casáis y Santaló, trad.) (vol. 2). Reus. 
Committee on Electronic Records. (1997). Guide for managing electronic records from an archival perspective. International Council on Archives. https://www.ica.org/sites/default/files/ICA\%20Study\%208\%20 guide_eng.pdf

Consejo de Gobierno del Tribunal Supremo Popular. (1983, 2 de mayo). Instrucción 108 de 1983. Juriscuba. http://juriscuba.com/wp-content/uploads/2015/10/Inst.-No.-108.pdf

Consejo de Gobierno del Tribunal Supremo Popular. (1983, 5 de julio). Dictamen 162 de 1983. Juriscuba. http://juriscuba.com/legislacion-2/dictamenes-tribunal-supremo/

Consejo de Ministros. (1988, 4 de febrero). Decreto 139. Reglamento de la Ley de Salud Pública. Gaceta Oficial Ordinaria n. ${ }^{\circ}$ 12. http://juriscuba.com/wp-content/uploads/2015/10/Decreto-No.-139.pdf

Cruz Mundet, J. R. (2011). Principios, términos y conceptos fundamentales. En J. R. Cruz Mundet (Dir.). Administración de documentos y archivos. Textos fundamentales (pp. 15-35). Coordinadora de Asociaciones de Archiveros. http://hdl.handle.net/10016/19730

Fonticoba Valdés L.M., Viña Camejo J., Tellería Prieto M.C., Faife Campaña M.A., Herrera Serrano B. (2018). Gestión de la historia clínica electrónica del servicio de Cirugía Refractiva. Rev Ciencias Médicas, 22(4), 783-92. http://www.revcmpinar.sld.cu/index.php/publicaciones/article/view/3413

García Millán, Á. (2019). El valor probatorio de la historia clínica como documento público. Derecho y Salud, 29(1), 145-154. https://www.ajs.es/index.php/es/index-revista-derecho-y-salud/volumen-29numero-1-2019/el-valor-probatorio-la-historia-clinica-como

García, H. (2017, 26 de mayo). Implantarán en Cuba la historia clínica digital. Juventud Rebelde. http://www. juventudrebelde.cu/cuba/2017-05-26/implantaran-en-cuba-la-historia-clinica-digital

Gutiérrez Barrenengoa, A. (2012). La historia clínica como prueba en el proceso judicial por responsabilidad médica. En O. Monje Balmaseda (coord.); F. Lledó Yagüe y L. Morillas Cueva (dirs.), Responsabilidad médica civil y penal por presunta mala práctica profesional (El contenido reparador del consentimiento informado) (pp. 323-334). Dykinson S.L.

Heredia Boada, E. I. (2015). Diseño de un sistema de gestión documental-digital para el archivo de historias clínicas del Subcentro de Salud Chillogallo [tesis de tecnología, Universidad de las Fuerzas Armadas]. Repositorio institucional ESPE. https://repositorio.espe.edu.ec/bitstream/21000/10999/1/TESPE-049012.pdf

Hernández Salvador, C. (2004). Modelo de Historia Clínica Electrónica para Teleconsulta Médica [tesis de doctorado, Universidad Politécnica de Madrid]. http://oa.upm.es/231/1/09200417.pdf

Herrán Ortiz, A. I. (2012). A propósito de la protección jurídica de los datos personales de salud. Luces y sombras de la historia clínica en el marco normativo español. En O. Monje Balmaseda (coord.); F. Lledó Yagüe y L. Morillas Cueva (dirs.), Responsabilidad médica civil y penal por presunta mala práctica profesional (El contenido reparador del consentimiento informado) (pp. 77-108). Dykinson S.L.

Jericó Ojer, L. (2018). Tratamiento médico, consentimiento y derecho penal. En Diego-M. Luzón Peña (Dir.), Libro Homenaje a Claus Roxin por su nombramiento como Doctor Honoris Causa por la Universidad Inca Garcilaso de la Vega (pp. 293-315). Universidad Inca Garcilaso de la Vega.

Juan Carlos I Rey de España. (2000, 7 de enero). Ley 1 de 2000. Ley de Enjuiciamiento Civil. BOE. https:// www.boe.es/buscar/pdf/2000/BOE-A-2000-323-consolidado.pdf 
Juan Carlos I Rey de España. (2002, 14 de noviembre). Ley 41 de 2002. Ley Gásica reguladora de la autonomía del paciente $y$ de derechos y obligaciones en materia de información y documentación clínica. BOE. https:// www.boe.es/buscar/pdf/2002/BOE-A-2002-22188-consolidado.pdf

Larena Beldarraín, J. (2012). El proceso por responsabilidad civil médica: Consideraciones en materia probatoria. En O. Monje Balmaseda (coord.); F. Lledó Yagüe y L. Morillas Cueva (dirs.), Responsabilidad médica civil y penal por presunta mala práctica profesional (El contenido reparador del consentimiento informado) (pp. 305-321). Dykinson S.L.

Lombana Villalba, J. (2010). Derecho penal y responsabilidad médica. Biblioteca Jurídica Diké.

Maier, J. (1996). Derecho Procesal Penal. Fundamentos (2. ${ }^{a}$ ed., vol. 1). Editores del Puerto.

Mantecón Ramos, A. (2014). Cien problemas de la prueba judicial en lo civil. Ediciones ONBC.

Martín Hernández, G. (2000). Manual de Derecho Procesal Civil I. Los Procesos de Cognición. Nica Ediciones.

Mejías Rodríguez, C. A. (2012). Falsedad y falsificación en documentos notariales. Excursus sobre la responsabilidad penal del notario. Anuario Iberoamericano de Derecho Notarial, 1, 317-345. https:// dialnet.unirioja.es/servlet/articulo?codigo $=4467375$

Mena Mugica, M. M. (2014). Orígenes y principios de la gestión documental. En M. E. Gómez Durán, Fundamentos de la Gestión Documental, de Información y del Conocimiento (pp. 41-73). Félix Varela.

Ministerio de Salud Pública. (2007, 9 de enero). Resolución 1. Reglamento General de Hospitales. Legislación. http://legislacion.sld.cu/index.php?P=FullRecordEID $=151$

Ministerio de Salud Pública. (2008, 17 de junio). Resolución 135 de 2008. Reglamento General de Policlínico. Legislación. http://legislacion.sld.cu/index.php?P=FullRecordEID $=155$

Monje Balmaseda, Ó. (2012). Los actos preparatorios del procedimiento judicial por responsabilidad médica. En O. Monje Balmaseda (coord.); F. Lledó Yagüe y L. Morillas Cueva (dirs.), Responsabilidad médica civil y penal por presunta mala práctica profesional (El contenido reparador del consentimiento informado) (pp. 121-132). Dykinson S.L.

Naciones Unidas. (1999). Ley Modelo de la Cnudmi sobre Comercio Electrónico. Guía para su incorporación al derecho interno con la 1996 con el nuevo artículo 5 bis aprobado en 1998. Publicación de las Naciones Unidas. https://bit.ly/3wYC7xE

Nieva Fenoll, J. (2010). La valoración de la prueba. Marcial Pons.

Nieva Fenoll, J. (2017). La inexplicable persistencia de la valoración legal de la prueba. Ars Iuris Salmanticensis, 5, 57-76. https://gredos.usal.es/bitstream/handle/10366/135945/La_inexplicable persistencia_de_la_valor.pdf;jsessionid=E5106FC6BEFB723A5BD060346F2CA964? sequence $=\overline{1}$

Parra Quijano, J. (2007). Manual de Derecho Probatorio (16. ${ }^{a}$ ed.). Librería Ediciones de Profesional.

Pérez Pérez, P. (2003). Delitos contra la fe pública. En C. A. Mejías Rodríguez, D. Rivero García, G. Rodríguez, R. de la Cruz, M. Goite Pierre, P. Pérez Pérez, Derecho Penal Especial (vol. 1) (pp. 269314). Félix Varela.

Ponjuán, G. (2008). Gestión de información: precisiones conceptuales a partir de sus orígenes. Informação. Informação, (13), 26-38. https://blogs.sld.cu/gretchen/files/2016/09/Ponjuan-08-precconc-Gest-Inf.pdf

Prensa Latina (2019, 27 de septiembre). La historia clínica digital se inicia en Cuba. Bohemia. http://bohemia. cu/salud/2019/09/la-historia-clinica-digital-se-inicia-en-cuba/ 


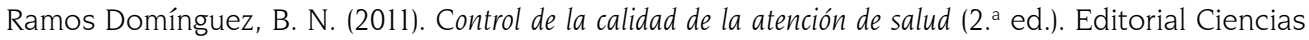
Médicas.

Real Academia Española. (2020). Diccionario de la lengua española. https://dle.rae.es/documento

Real Decreto (1889, 24 de julio). Código Civil de España. Gaceta de Madrid n. ${ }^{\circ}$ 206. https://www.boe.es/ buscar/pdf/2000/BOE-A-2000-323-consolidado.pdf

Rivero García, D., y Bertot Yero, M. C. (2013). Código Penal de la República de Cuba (Anotado con las Disposiciones del CGTSP). Ediciones ONBC.

Rives Seva, J. M. (2004). Consideraciones generales acerca de la responsabilidad civil médica y sanitaria. Cuestiones de Derecho sustantivo y procesal en la materia. La Ley, 3, 1629-1639. https://dialnet. unirioja.es/servlet/articulo?codigo $=852910$

Roxin, C. (2003). Derecho Procesal Penal (1. ${ }^{\text {a }}$ ed., 2. ${ }^{\text {a }}$ reimp.). Editores del Puerto.

Sada Contreras, C. E. (2000). Apuntes elementales de Derecho Procesal Civil. Universidad Autónoma de Nuevo León, Facultad de Derecho y Ciencias Sociales y Colegio de Criminología.

Salazar Santafe, P. A. (2017). La historia clínica en el proceso civil: una crítica a su empleo como principal medio de prueba en los casos de responsabilidad médica. [tesis de grado, Universidad Católica de Colombia]. Repositorio Institucional Universidad Católica de Colombia https://repository.ucatolica.edu.co/ handle/10983/15423

Serra Domínguez, M. (2009). Estudios de Derecho Probatorio. Communitas.

Silvia Velito, A., y Tejada Soriano, S. R. (2010). La historia clínica como instrumento de calidad [Curso]. Curso Anual de Auditoría Médica del Hospital Alemán. Hospital Alemán. http://www.auditoriamedicahoy. com/biblioteca/La\%20historia\%20cl\%C3\%ADnica\%20como\%20instrumento\%20de\%20calidad\%20 Tejada\%20Velito.pdf

Siso Martín, J. (2017, 18-19 de abril). La historia clínica su importancia en el proceso de responsabilidad sanitaria y su valor como medio probatorio [ponencia]. Curso "Responsabilidad sanitaria y la nueva configuración legal de la imprudencia médica, Centro de Estudios Jurídico, Madrid, España.

Taruffo, M. (2008). La Prueba (L. Manríquez y J. Ferrer Beltrán, trad.). Marcial Pons.

Tribunal Supremo-Sala Primera, de lo Civil. (2006, 14 de febrero). Sentencia 84/2006 (Juan Antonio Xiol Rios, M. P.). https://supremo.vlex.es/vid/responsabilidad-medica-nexo-causal-valoracion-20367681

Uzoatuegwu Roblejo, M. J. (2019). Riesgo médico-legal de las historias clínicas de pacientes con parto por cesárea primitiva [tesis de especialidad no publicada, Universidad de Ciencias Médicas, Santiago de Cuba].

Valenti, D. A. (2017). Riesgo médico-legal: ¿cómo evaluarlo? IntraMed. https://bit.ly/3eaRaMb

Vila Morales, D., y Pérez Echeverría, R. (2012). Principales instituciones del derecho médico y los instrumentos médicos jurídicos. Estudio de casos judiciales de derecho médico. En D. Vila Morales, Teoría del derecho médico (pp. 78-110). Editorial Ciencias Médicas.

Walne, P. (Ed.). (1988). Dictionary of archival terminology. English and French. With equivalents in dutch, german,

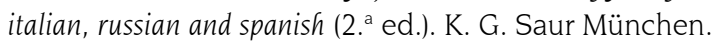

